\title{
ADENOID CYSTIC CARCINOMA MASQUERADING AS A BREAST LUMP: A CASE REPORT
}

\author{
Prashant Chandra Das ${ }^{1}$, Rahul Agarwal2, Madhusmita Patro ${ }^{3}$, Ritu Singhal ${ }^{4}$ \\ ${ }^{1}$ Senior Resident, Department of Surgical Oncology, Kidwai Memorial Institute of Oncology. \\ ${ }^{2} \mathrm{HOD}$, Department of Surgical Oncology, Jawaharlal Nehru Cancer Hospital, Bhopal. \\ ${ }^{3}$ Registrar, Department of Anaesthesiology, Jawaharlal Nehru Cancer Hospital, Bhopal. \\ ${ }^{4}$ HOD, Department of Pathology, Jawaharlal Nehru Cancer Hospital, Bhopal.
}

ABSTRACT: Adenoid cystic carcinoma of the breast is a rare histopathological entity accounting for $<1 \%$ of all breast cancers. Though morphologically similar to salivary gland neoplasms it carries a much better prognosis with a reported 10 year survival to be $90-100 \%$. Surgery forms the mainstay of treatment with both simple mastectomy and breast conservation surgery being performed followed by adjuvant systemic and radiotherapy. Awareness of this rare variant of breast carcinoma is required for optimal treatment planning and to avoid any diagnostic dilemnas.

KEYWORDS: Adenoid Cystic Carcinoma of Breast, Basaloid Carcinoma, Breast Cancer, Cylindroma, Triple Negative Breast Cancer.

HOW TO CITE THIS ARTICLE: Prashant Chandra Das, Rahul Agarwal, Madhusmita Patro, Ritu Singhal. "Adenoid Cystic Carcinoma Masquerading as a Breast Lump: A Case Report". Journal of Evolution of Medical and Dental Sciences 2015; Vol. 4, Issue 92, November 16; Page: 15817-15818, DOI: 10.14260/jemds/2015/2290.

INTRODUCTION: Adenoid cystic carcinoma (Basaloid carcinoma, Cylindroma) though frequently associated with salivary glands can also occur at other sites of the body with a exocrine secretory glandular function like the maxillary sinus, tracheobronchial tree, nasopharynx, breast, prostate, lungs and the uterine cervix.[1,2,3] Adenoid cystic carcinoma (ACC) of breast is a rare entity accounting for $0.1-1 \%$ of all breast cancers. ${ }^{[3,4]}$ Though morphologically ACC of the breast is similar to ACC of the salivary glands but it carries a much better prognosis with an excellent 10 year survival.[3] Management is similar to invasive breast cancer and consists of mastectomy, axillary clearance, breast conservation, chemotherapy and radiotherapy. Here we are reporting a 55 year old woman with a tumor of right breast which proved to be this rare breast neoplasia.

CASE SUMMARY: A 55year old postmenopusal woman presented with a history of lump in right breast for the 4years. Clinical examination revealed a well circumscribed $2 \mathrm{~cm}$ nodule in the upper outer quadrant of the right breast in close proximity to the nipple. The overlying skin was normal and there was no palpable axillary lymphadenopathy. Sonomammography revealed a $2.5 \times 2 \times 1.9 \mathrm{~cm}$ solid focal lesion in right breast subareolar region. No architectural distortion or micro calcification was seen. Skin and subcutaneous tissue appeared normal. It was graded as BIRADS 4 [Figure-1]. Fine needle aspiration cytology was suggestive of salivary gland tumor likely adenoid cystic carcinoma. She was treated with wide excision of the lump. Histopathologic examination showed a grayish white $2 \times 1 \times 1.5 \mathrm{~cm}$ lesion comprising of infiltrating tubules and cribriform like nests of basaloid epithelial cells showing monomorphic round nuclei and occasional small nucleoli.

Financial or Other, Competing Interest: None.

Submission 23-10-2015, Peer Review 24-10-2015,

Acceptance 04-11-2015, Published 16-11-2015.

Corresponding Author:

Dr. Prashant Chandra Das,

Room: 204, PG Mens Hostel,

Kidwai Memorial Institute of Oncology, Bengaluru.

E-mail:dr.munu.das@gmail.com

DOI:10.14260/jemds/2015/2290.
Histopathologic examination showed a grayish white $2 \times 1 \times 1.5 \mathrm{~cm}$ lesion comprising of infiltrating tubules and cribriform like nests of basaloid epithelial cells showing monomorphic round nuclei and occasional small nucleoli. These cell nests were punctated by cystic spaces and cells arranged haphazardly around spaces [Figure 2].

DISCUSSION: Adenoid cystic carcinoma of breast commonly presents in an adult perimenopausal female as a breast lump which may or may not be painful. The associated pain has been reported to be due to contractile myoepithelial elements of these tumors and not due to perineural invasion which is uncommon in these tumors. [4,5] It is usually unilateral. [6] This rare histopathologic entity of the breast is characterized by slow progression and good prognosis. A 90-100\% 10-year survival rate is reported, and metastases to lymph-node and visceral organs is rare. $[7,8]$

There is a paucity of literature on ACC breast due to the rarity of this disease with most studies being either case reports or cohorts. Geschickter first described adenoid cystic carcinoma of the breast. Galloway et al (1966) at Mayo clinic reported nine cases of adenoid cystic carcinoma occurring in the breast.[1] ACC mostly present as a unilateral breast lump which might be painful. There is a predilection for the periareolar region though all quadrants can be affected.[3,5] In our case it was a painless lump located in the upper outer periareolar region of the right breast. ACC has been reported to be found in conjunction with ipsilateral.[7] and contralateral breast cancer. An association with microglandular adenosis has also been reported.[9,3] with certain authors suggesting that ACC arises in the background of microglandular adenosis.

The various growth patterns found in ACC breast are similar to those found in salivary glands: the classic cribriform pattern, as well as the solid, trabecular and glandular patterns. $14 \%$ of cases may show sebaceous differentiation and foci of adenosquamous differentiation may also be encountered.[3,4] 
The finding of a biphasic pattern of true lamina and pseudolamina and a biphasic cellular pattern of myoepithelial and epithelial cells is diagnostic of ACC. ACC breast shows triple negative phenotype i.e. lack of expression of ER, PR and HER2.[3,10] In our case the histology showed a cribriform growth pattern and immunohistochemistry showed a triple negative phenotype.

The prognosis of ACC is related to the histological grade. According to the grading given by Ro et al.[11] ACC are graded according to the proportion of solid growth - cases with either cribriform or glandular pattern are considered low grade/ G1 tumours, cases with $<30 \%$ of solid elements are labelled as G2, whereas cases showing $>30 \%$ of solid growth are classified as high grade/G3 tumours. With the increase in the percentage of solid elements, the risk of tumor development and postoperative recurrence also rises.[3,11,12]

Surgery remains the mainstay of treatment with both BCS and mastectomy described in literature. Simple mastectomy is the preferred treatment modality used by most surgeons due to the rarity of lymph node involvement by this tumor; its lower morbidity; and faster recovery.

\section{REFERENCES:}

1. Anthony PP, James PD. Adenoid cystic carcinoma of the breast: prevalence, diagnostic criteria, and histogenesis. J. clin. Path., 1975, 28, 647-655.

2. Dodd RL, Slevin NJ. Salivary gland adenoid cystic carcinoma: a review of chemotherapy and molecular therapies. Oral Oncol. 2006; 42(8):759-769.

3. Marchio C, Weigelt B, Reis-Filho JS. Adenoid cystic carcinomas of the breast and salivary glands (or 'The strange case of Dr. Jekyll and Mr. Hyde' of exocrine gland carcinomas). J Clin Pathol 2010; 63:220-228.

4. Rosen PP. Adenoid cystic carcinoma. In: Rosen PP, ed. Rosen's breast pathology. Philadelphia: Lippincott Williams and Wilkins, 2009:590-604.

5. Bennett AK, Mills SE, Wick MR. Salivary-type neoplasms of the breast and lung.Semin Diagn Pathol 2003;20:279304.

6. Law YM, Quek ST, Tan PH, Wong SL: Adenoid cystic carcinoma of the breast. Singapore Med J 2009, 50:8-11.

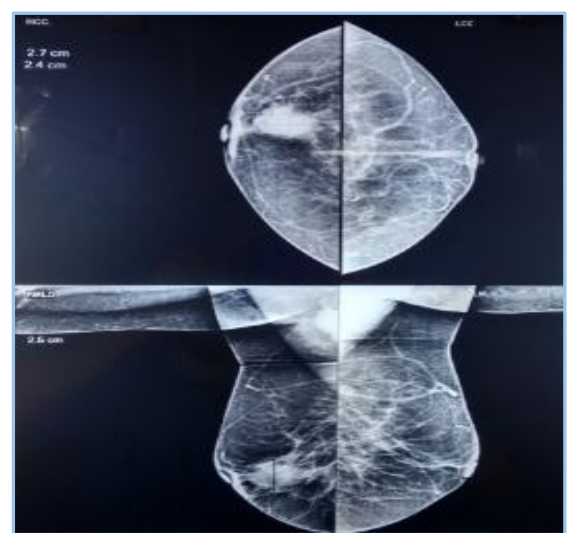

Fig. 1: Mammogram showing the tumor in subareolar region of right breast
However adjuvant systemic or radiation therapy is usually recommended due to the high recurrence rates of simple mastectomy.[12] The proposed treatment according to the pathological grading suggested by Ro et al.[11] is simple lumpectomy for grade 1 tumors, simple mastectomy for grade 2 tumors and mastectomy with axillary clearance for grade 3 tumors.

Due to the rarity of this disease the optimal treatment is yet to be determined. There are a few studies on hormone therapy, adjuvant chemotherapy and bio-immunotherapy and prospective trials are needed to determine the optimal treatment.

CONCLUSION: Adenoid cystic carcinoma of breast is rare and forms a diagnostic and therapeutic challenge for the clinician with a lack of consensus regarding the optimal treatment. More studies and prospective trials are required to further characterize the lesion and arrive at a consensus for treatment.

7. Kontos M, Karles D, Petrou A and Alexandrou PTH. Adenoid cystic carcinoma intermingled with ductal carcinoma of the breast: a case report and review of the literature. Journal of Medical Case Reports 2011, 5:437.

8. Kontos M, Fentiman IS: Adenoid cystic carcinoma of the breast. Int J Clin Pract 2003, 57:669-672.

9. Acs G, Simpson JF, Bleiweiss IJ, et al. Microglandular adenosis with transition into adenoid cystic carcinoma of the breast. Am J Surg Pathol 2003;27:1052-60

10. Azoulay S, Lae M, Freneaux $P$, et al. KIT is highly expressed in adenoid cystic carcinoma of the breast, a basal-like carcinoma associated with a favorable outcome. Mod Pathol 2005; 18:1623-31.

11. Ro JY, Silva EG and Gallager HS: Adenoid cystic carcinoma of the breast.

Hum Pathol 18: 1276-1281, 1987.

12. Shaohua wang, Xiangjun Ji, Yao Wei, Zeping Yu and Ning LI. Adenoid cystic carcinoma of the breast: Review of the literature and report of two cases. Oncology letters. 2012;4: 701-704.

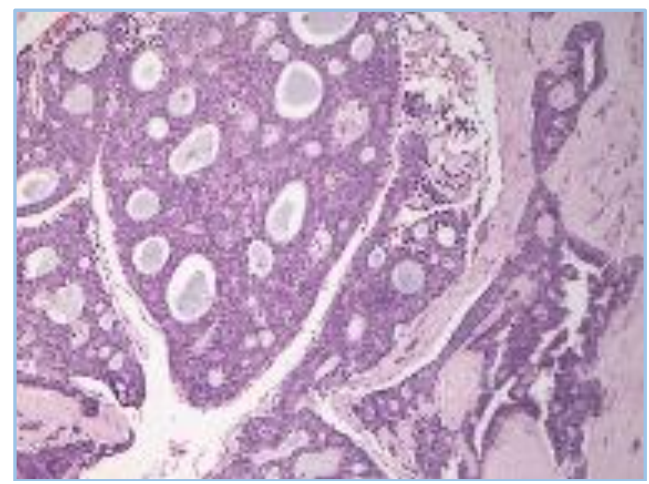

Fig. 2: Micrograph representing Adenoid cystic carcinoma of breast. Cribriform pattern is seen consisting of islands of basaloid tumor cells separated by myxoid hyaline stroma (H \& E stain, 10X) 